\title{
International R\&D and Manufacturing Networks: Dynamism, Structure and Absorptive Capacity
}

\author{
Patricia Deflorin $^{1}$, Maike Scherrer-Rathje ${ }^{2}$, and Helmut Dietl ${ }^{1}$ \\ ${ }^{1}$ Department of Business Administration, University of Zurich, Switzerland \\ (patricia.deflorin, helmut.dietl) @business.uzh.ch \\ ${ }^{2}$ Institute of Technology Management, University of St. Gallen, Switzerland \\ maike.scherrer@unisg.ch
}

\begin{abstract}
We analyze the absorptive capacity (AC) process of a manufacturing company with central $R \& D$ and an internationally distributed manufacturing network. Prior research shows that an implementation of the lead factory (LF) is especially supportive if the international manufacturing network struggles with implementing new products and processes. We analyze determinants of AC and show that, in addition to prior related knowledge of the receiving plant, structure can have an even stronger influence. We show that in the case of a low level of prior related knowledge and a low level of AC within the receiving plants as well as high technological heterogeneity between plants and LF, the implementation of an LF may not lead to the expected result. In addition, we conclude that the analysis of the AC process has to move from a single unit to a network. This helps to understand the AC concept in the context of multinational companies.
\end{abstract}

Keywords: Absorptive capacity, Lead factory, New product introduction.

\section{Introduction}

Developing and maintaining absorptive capacity (AC) is critical to the long-term survival and success of a company. We apply the sequential process framework of AC as proposed by Lane et al. (2006): recognizing and understanding potentially valuable new external knowledge through exploratory learning, assimilating new knowledge through transformative learning, and using the assimilated knowledge to create new knowledge through exploitative learning.

It is our purpose to show, based on the analysis of a new product introduction (NPI) within a manufacturing company with internationally distributed plants, how organizational antecedents, specifically structural drivers and related prior knowledge influence the efficiency and effectiveness of the AC process. To understand the AC output, we must consider its activities, starting with $R \& D$ and ending with the production of the product. An analysis of the AC process must supersede an isolated focus on $\mathrm{R} \& \mathrm{D}$ activities. The AC process must instead span over the R\&D and production network. We analyze the assumption that the Lead Factory (LF) concept helps to overcome a low level of prior related knowledge in the receiving plants and a low $\mathrm{AC}$ 
level. The implementation of an LF concept aims to support the knowledge of receiving plants. Therefore, if the level of prior related knowledge of the plants differs within the international production network, the implementation of an LF concept could be a solution that would improve the efficiency and effectiveness of the AC process and its outcome. We highlight the usefulness of the lead factory concept. Further, we show that, despite a low level of prior related knowledge within the receiving plants, the implementation of the lead factory concept may still not be sufficient and may result in a lower level of AC efficiency and effectiveness than expected.

\section{Review: Organizational Antecedents, AC and Outcome}

Many researchers have analyzed the different factors influencing the AC process and its outcomes. Based on a literature analysis, Volberda et al. (2010) have developed an integrative framework of AC. The framework consists of managerial antecedents, intra-organizational antecedents, inter-organizational antecedents, and prior related knowledge. These factors are assumed to influence the efficiency and effectiveness of the AC process. Further, environmental conditions moderate the AC process and its outcome. We focus our analysis on intra-organizational antecedents, more specifically, the influence of the organizational form on the AC process as well as the relationship to prior related knowledge (see Fig. 1).

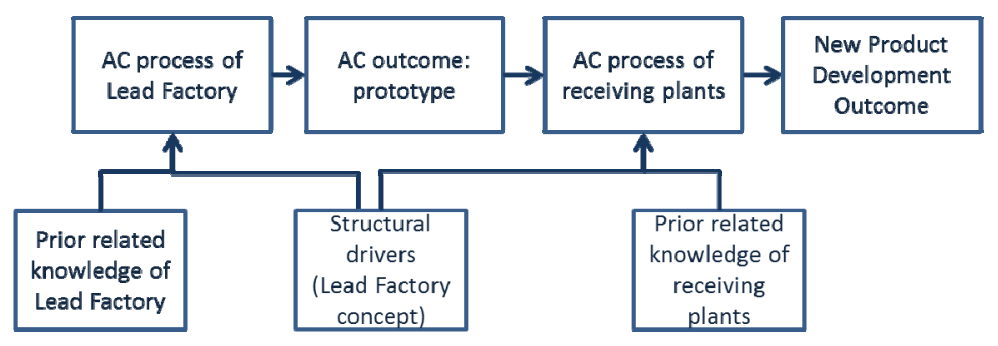

Fig. 1. The lead factory concept and its influence on AC outcome

\subsection{AC Process}

We apply the multidimensional view of AC as proposed by Cohen and Levinthal (1990) and Lane et al. (2006). The first step in the process entails the exploratory learning needed to recognize and understand new external knowledge. The second dimension focuses on the assimilation of knowledge through transformative learning. Finally, the third dimension focuses on exploitative learning and how it is used to assimilate new knowledge. The separation between the three different dimensions of $\mathrm{AC}$ helps to recognize the different nature of the processes in achieving an understanding of the relationship between the factors influencing the efficiency and effectiveness of the $\mathrm{AC}$ process and the $\mathrm{AC}$ process itself. 


\subsection{Structural Drivers of the Lead Factory Concept}

We focus our analysis on the internal drivers of $\mathrm{AC}$, specifically the organizational structure of a firm. A firm's knowledge base cannot be separated from its organizational structure (Grant, 1996). Lane et al. (2006) highlight the need to focus attention on the structure, policies, and processes within the organization that affect knowledge transfer, sharing, integration, and creation. They highlight the importance of understanding the influence of these factors, as they seem to drive the efficiency and the effectiveness of the firm's AC (Lane et al., 2006). We focus our analysis on the structure of the lead factory concept and how such a structure influences the efficiency and effectiveness of the AC process.

The link between R\&D and manufacturing with respect to the success of new product introductions (NPI) has been analyzed and proven important in many studies (Kessler and Chakrabarti, 1999, Swink, 1999). Many problems in NPI can be traced to a lack of R\&D-manufacturing coordination (Swink, 2003). To overcome these coordination issues, companies have started to implement a lead factory (Ferdows, 1997). A lead factory is the strategic heart of the manufacturing network, as it links $R \& D$ and the manufacturing department and acts as a knowledge incubator. It translates R\&D knowledge into manufacturing knowledge (Deflorin et al., 2012). It also develops the production processes and documents and produces the prototype. In addition, the employees of the lead factory support the production ramp-up within the receiving plants. The role of the lead factory, also called the center of excellence, has been the focus of several studies (Leonard-Barton, 1995, Ferdows, 1997, Frost et al., 2002). We assume that the lead factory concept influences the efficiency and effectiveness of the AC process and its outcome. We therefore analyze how the structural drivers of the lead factory concept influence the AC process of the lead factory and the receiving plant.

\subsection{Prior Related Knowledge}

Prior related knowledge is often seen as a most important antecedent to AC (Cohen and Levinthal, 1990). Existing knowledge helps in the recognition of new knowledge and its assimilation. In addition, plants with a low level of prior related knowledge are often in need of external support (e.g., a lead factory). The importance of prior related knowledge, however, has been challenged. We analyze how the factors "prior related knowledge" and "structural drivers" jointly influence the AC process and its outcome.

\subsection{AC Outcome}

Research on AC is often focused on R\&D, and output is measured with innovationrelated performance measures or is directly linked to overall firm performance (Volberda et al., 2010). As we expand the research focus on the process of new product introduction (from R\&D to serial production), we measure the efficiency and effectiveness of the NPI output. 


\section{$3 \quad$ Methodology}

We applied a qualitative case study approach in order to gain new insights into the relationship between structure, prior related knowledge, the AC process, and NPI output. Thus, we collected data from each of the AC process steps by employees responsible for implementing new products through structured interviews. In addition, we attended meetings of NPI project leaders and analyzed archival sources. This exploratory research method embodies the theory-building approach of Yin (1994) and Eisenhardt (1989). The unit of analysis is the NPI process of a Swiss manufacturing company called Machinery, Inc. The analyzed NPI was started within the central R\&D department. The following process steps were investigated: development (R\&D), prototyping (lead factory), and serial production (receiving plant).

\section{Case Analysis: Transferring Knowledge between R\&D, LF and CN Plant}

Machinery Inc. has a central R\&D department, a lead factory (LF) and decentralized plants. The following analysis focuses on the link between $R \& D$, LF and a receiving plant in China $(\mathrm{CN})$. Machinery Inc. is a traditional machinery producer with strong and experienced R\&D and production departments in Switzerland. Due to the increasing price pressure and the growing market in China, Machinery Inc. decided to build a new plant in the country. To help the Chinese plant develop the required capabilities and knowledge stock, the company decided to implement the lead factory concept. The Swiss plant acts as a lead factory. It is highly interlinked to the R\&D department, translates the developed product into production requirements, and develops the first prototype/product and the respective processes. The knowledge required to produce the machine is then transferred to the Chinese plant $(\mathrm{CN})$, the receiving plant. The $\mathrm{CN}$ plant translates the new knowledge into its own operating environment, adapts procurement and starts producing the serial production.

\subsection{LF Concept, Prior Related Knowledge and AC Process Outcome of the LF}

To translate external knowledge into new products, $R \& D$ recognizes, assimilates and applies knowledge (Lane et al., 2006). This knowledge is then transferred to the LF. The LF recognizes and assimilates knowledge and translates the R\&D material (e.g., drawings) into production knowledge. Concretely, the department develops processes required to develop the first prototype. The assimilated knowledge is then translated into applied knowledge - the production of the prototype.

The implementation of the LF concept has led to the following structural drivers which influence the AC process of the LF. First, R\&D and LF are part of the same cultural background and speak the same linguistic language. The plants are physically close, and there is intensive formal and informal information sharing. The relationship 
between R\&D and LF is strong, as the employees have known each other for many years. These structural drivers positively influence the AC process of the LF.

Both departments are experts in their respective fields. Due to the many NPIs during the last 50 years, both departments have a high level of related knowledge. This knowledge helps the LF employees to recognize knew knowledge and assimilate it. The prior related knowledge has a strong influence on the efficiency and effectiveness of the AC process. The employees of the LF are familiar with NPI and the recognition and translation of $\mathrm{R} \& \mathrm{D}$ information into the production environment. Therefore, the prior related knowledge of the LF positively influences the AC process and leads to a fast and dependable AC output; i.e., the prototype.

The LF employees state that the assimilation, transformation and application of the transferred knowledge do not lead to difficulties because of the structural drivers and the prior related knowledge stated above. The number of loops needed to adapt the $\mathrm{R} \& \mathrm{D}$ output to the LF's production requirements is low and because of the structural drivers of the concept and the related prior knowledge, effective and efficient. The output of the LF's AC process, i.e., the prototype of the new product, is dependable, fast and achieves a high quality level. The left side of Fig. 2 summarizes the findings.

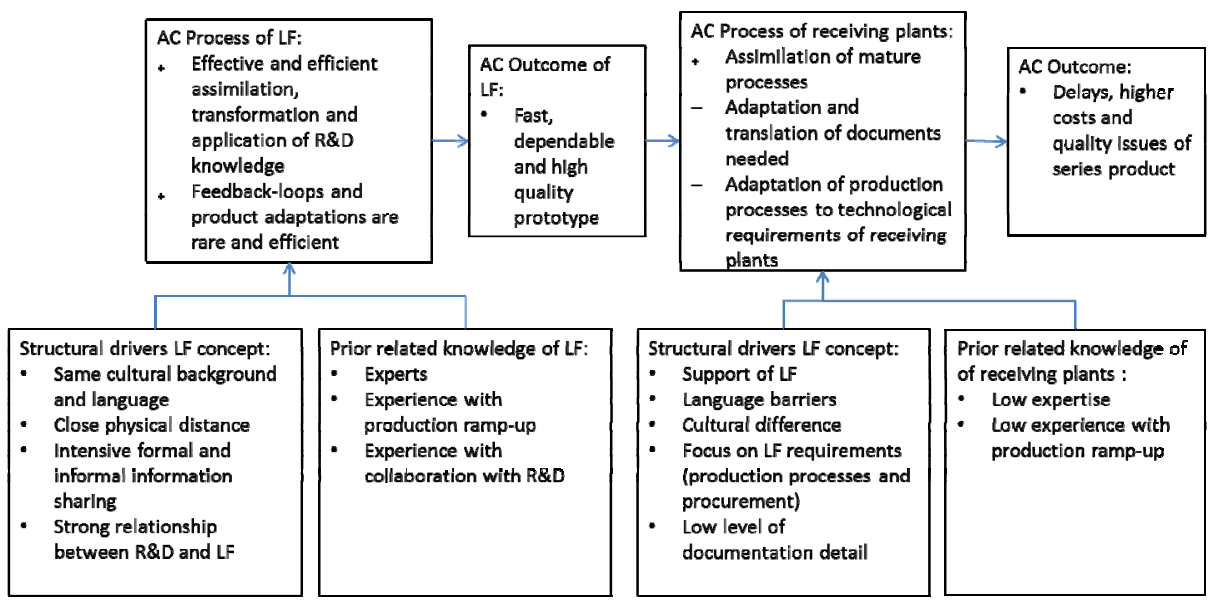

Fig. 2. The LF concept, prior related knowledge, AC process and outcome

\subsection{LF Concept, Prior Related Knowledge and AC Process Outcome of the Receiving Plant}

The $\mathrm{CN}$ plant receives the knowledge transferred from the LF. The receiving plant must recognize the new knowledge, transform it into its own production requirements and apply it with the goal of reaching serial production of the new product.

The transferred process and product documentation are of high quality. The R\&D documents have already been improved based on the input gained while producing the prototype. Therefore, the AC outcome of the LF positively influences the AC process of the receiving plant. 
Considering the structural drivers, a mixed influence on the AC process of the receiving plant is visible. Due to the intermediary responsibilities of the LF, employees support the transfer and help the $\mathrm{CN}$ employees to recognize and assimilate the new knowledge. The recognition and assimilation, however, is negatively influenced through language barriers and cultural distance. Documents have to be adapted and translated, leading to a negative influence on the efficiency and effectiveness of the AC process. The central $R \& D$ is focused on the requirements of the LF. R\&D employees are well informed about the equipment and capabilities of the Swiss plant and develop the product accordingly. Further, the production process and its documentation are developed according to the specifications of the Swiss plant. In addition, the procurement is also focused on the Swiss requirements. Therefore, the assimilation and application of the knowledge within the LF only partly supports the AC process within the $\mathrm{CN}$ plant. In addition, due to the close and long-term relationship between $\mathrm{R} \& \mathrm{D}$ and LF, the documentation is not as detailed as it should be in order to allow an easy and fast adaptation of the documents and processes. The transformation needed within the $\mathrm{CN}$ plant is time consuming and often results in a lower quality level of the final product than the prototype constructed from the lead factory. Despite the positive effect of the LF concept, depending on the intensity of the aforementioned factors, the negative effects may have a stronger influence on the efficiency and effectiveness of the AC process.

After the assimilation of the transferred knowledge, full serial production begins (application). The low labor and material cost advantage should lead to a better cost performance. However, as the machines were constructed according to Swiss standards and only partially adapted, some of the anticipated cost savings were not achieved. For example, the engine of the machine was still delivered from the Swiss standard supplier because the $\mathrm{CN}$ plant did not have enough time and experience to define a comparable supplier. In addition, the production employees did not have the capabilities to improve the processes designed to achieve additional cost savings.

The analysis of the influence of the prior related knowledge available at the $\mathrm{CN}$ plant revealed the following issues. Due to the relatively young age of the plant, employees do not have the same experience and expertise as their Swiss counterparts. Despite being in the position to receive an already-tested product and documentations from the LF, the structural drivers of the LF concepts necessitate that the knowledge received be transformed into its own production requirements. This transformation is difficult and time consuming, as $\mathrm{CN}$ plant employees are not used to assimilating knowledge or adapting and improving production processes; the respective prior knowledge is missing, and the AC level is low.

Based on the output of the central units (R\&D and LF) and the AC process of the $\mathrm{CN}$ plant, the NPI leads to the following results. The prototype was produced quickly and was proven dependable with a high level of quality. The recognition, assimilation and application process within the $\mathrm{CN}$ plants, however, was time consuming and the delivery of the series was delayed. In addition, there was a quality difference between the prototype and the $\mathrm{CN}$-produced machines; for example, the machines were produced with different types of steels, and the CN steel was not rust free. The expected costs were only partially achieved. The strong focus on the Swiss production requirements prevented a successful transfer and full cost-saving potential. 


\section{Discussion}

Machinery Inc. has invested in new plants in order to become internationally competitive and to be able to serve new and expanding markets. The new plants, however, have difficulties in recognizing, assimilating and applying knowledge. The supporting activities from the LF were implemented to strengthen the AC process within the receiving plant. The analysis of the structural drivers from the lead factory concept reveals that the concept has its weaknesses, which became visible while analyzing the efficiency and effectiveness of the AC process. The main structural issue of the LF concept stems from the focus of the LF requirements, leading to new assimilation needs within the receiving plants. The need to assimilate knowledge within the receiving plant is still present if the receiving plant has built up its knowledge stock. These negative effects out of the structural drivers of the lead factory, however, would not apply if the LF and the receiving plant applied identical technologies and process steps. Therefore, the higher the technological heterogeneity between the plants, the lower the positive effects of the structural drivers of the LF concept.

The analysis of the AC processes of the LF and receiving plants leads to a different structural possibility for Machinery Inc. To overcome the issues related to the strong focus on the LF's requirements, central R\&D could transfer the knowledge to a local team of developers (application development). The application developers would know the requirements of the $\mathrm{CN}$ plant and would therefore be able to adapt the documents to the local needs. In addition, this structural solution should strengthen the efficiency and effectiveness of the AC process of the $\mathrm{CN}$ plant as there are no language barriers between the application developers and the plant. In addition, there would be only a short distance and no cultural differences. This solution would ensure the assimilation of the transferred knowledge and allow an efficient and effective application without neglecting local advantages and without the additional costs of a lead factory.

\section{Conclusion}

We strengthen the construct of AC in exploring its important determinants. We argue that, in addition to prior related knowledge as a determinant of AC, structure can have an even stronger influence. Further, we show that the activities described in the AC process framework span different network units (R\&D, LF and plants). The consequences of the chosen structural solution reveal that an analysis of the AC process and outcome should span the whole network and move away from the single analysis of the $R \& D$ activities. Therefore, the unit of analysis moves from a single unit to a network. This helps in the understanding of the AC concept in the context of multinational companies.

Our framework shows the relationship between organizational structure and AC. More specifically, we analyze the effect of the lead factory concept. The analysis of Machinery Inc. shows that in the presented circumstances, the negative effect from the chosen structural solution seems stronger than the positive effects from the 
supporting activities of the LF. We therefore come to the preliminary conclusion that it is important to understand under which circumstances the lead factory concept is more or less suitable. Technological heterogeneity between the plants may reduce the positive effect of the LF concept and lead to a lower efficiency and effectiveness of the AC process than expected. The lead factory concept seems to be most suitable if there is high technological homogeneity between the plants and if the LF and the AC levels of the receiving plants are sufficiently high. Otherwise, the support of the lead factory may still be insufficient to assimilate and apply the transferred knowledge.

From a managerial perspective, different structural solutions must be implemented to strengthen the AC output. Based on the results of this single case study, we propose that in the case of high technological homogeneity, the implementation of an LF may be suitable. In the case of high technological heterogeneity, however, the strengthening of the AC output may be supported with the implementation of a local application development to overcome the negative influence of the LF's structural drivers on the efficiency and effectiveness of the AC process.

\section{References}

Cohen, W.M., Levinthal, D.A.: Absorptive Capacity: A New Perspective on Learning and Innovation. Administrative Science Quarterly 35, 128-152 (1990)

Deflorin, P., Dietl, H., Lang, M., Scherrer-Rathje, M.: The Lead Factory Concept: Benefiting from an Efficient Knowledge Transfer. Journal of Manufacturing Technology Management 23, 517-534 (2012)

Ferdows, K.: Making the Most of Foreign Factories. Harvard Business Review 75, 73-88 (1997)

Frost, T.S., Birkinshaw, J.M., Ensign, P.C.: Centers of Excellence in multinational corporations. Strategic Management Journal 23, 997-1018 (2002)

Grant, R.M.: Prospering in Dynamically-Competitive Environments: Organizational Capability as Knowledge Integration. Organization Science 7, 375-387 (1996)

Kessler, E.H., Chakrabarti, A.K.: Speeding Up the Pace of New Product Development. Journal of Product Innovation Management 16, 231-247 (1999)

Lane, P.J., Koka, B.R., Pathak, S.: The reification of absorptive capacity: A critical review and rejuvenation of the construct. Academy of Management Review 31, 833-863 (2006)

Leonard-Barton, D.: Wellsprings of Knowledge. Harvard Business School Press, Boston (1995)

Swink, M.: Completing projects on-time: how project acceleration affects new product development. Journal of Engineering and Technology Management 20, 319-344 (2003)

Swink, M.: Threats to new product manufacturability and the effects of development team integration processes. Journal of Operations Management 17, 691 (1999)

Volberda, H.W., Foss, N.J., Lyles, M.A.: Perspective - Absorbing the Concept of Absorptive Capacity: How to Realize Its Potential in the Organization Field. Organization Science 21, 931-951 (2010) 